Borneo Journal of Sciences \& Technology, Volume (3), Issue (1), Pages: 77-92

DOI: http://doi.org/10.3570/bjost.2021.3.1-11

e-ISSN: 2672-7439

(C) 2018, UCTS Publisher.

Submitted: $01^{\text {st }}$ September $2020 \quad$ Accepted: $07^{\text {th }}$ November $2020 \quad$ Published: $31^{\text {st }}$ January 2021

\title{
Causes and Effects of Ineffective Communication on Construction Projects
}

\author{
${ }^{1}$ Bernard Inibuh OBONADHUZE, ${ }^{2}$ Chidiebere Emmanuel EZE, ${ }^{3}$ Lawrence Uche SIUNOJE, \\ and ${ }^{4}$ Onyinye SOFOLAHAN
}

\author{
${ }^{1}$ Quantity Surveying Technology Department, Delta State Polytechnic, Ozoro, Nigeria \\ ${ }^{2}$ Quantity Surveying Department, Federal University of Technology, Owerri, Nigeria \\ ${ }^{3}$ Building Technology Department, Delta State Polytechnic Ozoro, Nigeria \\ ${ }^{4}$ Quantity Surveying Department, Lagos State Polytechnic, Nigeria
}

\begin{abstract}
A lot of failures and poor project performances reported on construction projects have been blamed on communication related problems. The effects of ineffective communication are usually high and they result from factors emanating from the management systems of construction organisations. This study examined the causes and effects of ineffective communication on construction projects. A well-structured questionnaire and snowball sampling techniques were adopted in gathering data from construction professionals in both private and public construction organisation in Delta state, Nigeria. With a reliability index of over 0.80, the gathered data were analysed using frequencies, percentages and relative importance index (RII). A fishbone diagram was also used to show the key findings of this study. The study revealed that construction organisations are still lagging behind in the practice of effective communication and that the major factors responsible for ineffective communication are management and leadership abilities, lack of training and undertrained workers, lack of support for advanced communication technologies, malfunction and/or use of out-dated technology, and poor communication skills. The major effects of ineffective communication on construction projects are; cost overrun, time overrun, high accident rate, wrong execution of activities, and rework and redesign occurrence. Effective communication practices are a great project integration tool that guarantees successful delivery of construction projects. Thus, experienced project managers with sound leadership capabilities should be engaged for sustainable communication practices.
\end{abstract}

Keywords: Ineffective communication, Communications channels, Construction project performance, Construction organisations, Nigeria.

\section{INTRODUCTION}

The construction industry is a vital sector responsible for the massive infrastructural provision and economic growth and development of countries [1]. The construction industry depends on the performance and successes of the various players such as (public and private clients, consultants, contractors, suppliers, subcontractors, professionals, tradespeople and the project community) to deliver the needed infrastructure and facilities. These participants are bound together in the delivery of construction projects through contractual agreements, and they required effective communication and collaboration to succeed. Construction project needs effective collaboration and coordination among diverse construction experts and client [2]. Similarly, Calvert et al. [3] submitted that for a construction project to achieve its target there must be an effective cooperation and information exchange among the participants. Furthermore, effective communication, evaluation and feedback to the construction project team at every phase of the construction project execution could assist in achieving project aim [4].

The success of construction organisations rely on the quality and effectiveness of the relationship between clients, professional, contractors, subcontractors, technical workers and regulatory bodies [5]. Relationship in construction contracts depend on communication and information exchange. This is because construction projects are information and data laden, which needs to be communicated across all facet of the organisations, and across the construction supply chain. Furthermore, communication across departments, between managers and employees,

Corresponding Author: Chidiebere Emmanuel Eze; Quantity Surveying Department, Federal University of Technology Owerri;

Email: emmanuel.eze@ futo.edu.ng. 
customers and employees, employees and vendors are all indispensible to how the day-to-day activities of organisations are discharged [6]. Olanrewaju et al. [7] and Aiyewalehinmi [8] submitted that effective communication involves the flow and exchange of information and ideas from one worker to another at all stages of the construction project.

Communication in the Nigerian construction industry is not effectives as evident in the regular project delivery problems similar to what are obtained in other emerging and developed countries of the world [9]. Also, communication problems have resulted to the persistent lack of share understanding of project specifics in the Nigerian construction industry. Communication ineffectiveness among parties to a contract on construction projects have resulted to majority of the failures of construction projects in Nigeria. Poor communication has been blamed for time and cost overruns, waste, health and safety issues, rework and quality problems, and decline in productivity, conflicts, disputes and claims, among other issues that impact on project delivery. Information that needs to be communicated include; drawings, specifications, construction methods, variation orders and instructions, among others [10]. When this information is poorly managed, it could lead to demotivated workforce, design errors, production failure, and slowdown of activities [11]. These problems are caused by the poor performance in areas of communication and information exchange among the parties to construction projects [1]. Therefore, construction organisations need to implement appropriate communication management system to be able to overcome the negative impact of poor communications on construction projects.

The consequences of poor communication on construction projects could derail organisations profit, reduce revenue generation, impact on client satisfactory and even loss of clients; these could impact on the performance and survival of construction organisations. Thus, Kokemuller [12] posits that poor communication restricts an organisation's capability to improve performance. Anton [13] submit that ineffective communication in the workplace could lead to friction, frustration and an unfriendly environment where motivation is threaten, thus, leading to poor productivity. The lack of motivation could also reflect on how workers relate with clients and potential customers. Effective communication occurs when the intended meaning of a communicated message is not misunderstood. Ineffective communication is a product of interference or noise during the transmission of the message across the medium of channel of communication. The noise interferes and distort the original meaning of the information contained in the message, thus, leading to breakdown, loss of quality and wrong decoding evident in the feedback. These noises constitute impediments that compromise information exchange and ideas sharing. It is the contributors to ineffective communication on construction projects that this study set to assess.

Based on the foregoing, this study examined the factors responsible for ineffective communication on construction projects with a view to determining the effects of poor communication and to recommend possible measures for eliminating the causes and effects for better project performance. The outcome of this study will provide construction organisations with information they should focused on during construction project communications planning. Also, Efforts should be made to put in place an effective strategy for driving effective communication system across the entire construction value chain and organisational hierarchy. Effective communication guarantees improvement in project performance. It is only when the causes of poor communication are identified and examined that measures for eliminating them and improving the line of communications in an organisation can be put in place [13]. This study will also add to available literature on communication in construction management studies.

\section{LITERATURE REVIEW}

\section{Organisational Communication}

Generally, communication is the exchange or sharing of information, emotions, and thoughts between individuals in a group or within an organisation, or between groups and /or organisations [14]. A fundamental role of communication is to bring about a balance of individual and organisational objectives. According to Nebo et al. [15], communication leads to changes, and it is the mainstream of any organisation growth. Furthermore, communication leads to interaction and understanding in the relationship between management and employees that normally would bring about increase in performance of all parties involved in the chain of communication. Communication according to Stephen [16] is one of the critical factors required for directing and mobilizing organisational workforce towards meeting the organisations' goals. Communication is therefore, essential for creating an atmosphere of understanding and co-operation that promote individual and organisational performance and progress. An organisation that is marred with communications inconsistencies/ineffectiveness is a non-progressive organisation.

Like every type of organisation, construction organisations, uses three major means of communication in discharging it day-to-day activities. 
They are written communication involving the use of notices, reports, memos, bulleting; to communicate within and outside of the firms [17]. Another means of communication is the verbal communication which involves face-to-face interaction between two or more persons in an organisation; this is the mean used in meetings, conferences, seminar, and interviews, among other. In verbal communication, the level of interaction between the sender and receiver is high [17]. Nonverbal Communication is another means of communication that involves the use of gestures, charts, graphs, drawings, symbols, pictures; to share information and knowledge.

\section{Communication management in construction projects environment}

In the construction industry, effective communication is a core competency element to the successful delivery of construction projects [18]. Achieving effective communication has remained a challenging task owing to the fragmented, dynamic and the multitude of stakeholders involved in construction projects that needs to be communicated to. According to Ishaq et al. [19], information sharing and dissemination amongst the participants of construction projects is vital towards the realisation of the objectives of the projects. Design, production, organisation and management are the stages of construction project where communication plays an importance role to ensure their actualisation [11].

Construction project communication management is not simple and straight forward but requires series of processes and steps to ensure it is effective in assisting construction organisations in meeting project goals. According to PMBOK Guide [20], project communication management involves all the processes that are needed to guarantee timely and proper planning, collection, creation, distribution, storage, retrieval, management, control, monitoring, and the ultimate disposition of project information. Communications management involves planning of communications, managing communications and controlling communication. Project integration is a key function of the project manager, and in doing this, the project manager spent over $90 \%$ of the time communicating. According to Antonio and Senol [21], interpersonal skill like the communication skills play a critical role in the delivery of projects, as construction business is service based. Every deliverable or outcome of a project need to be communication, and communication is the means of integrating other knowledge areas of project management. This is based on the understanding that the work of integrating all facets of the project (i.e. man, money, material, equipment and other resource), involves a carefully planned and properly managed and controlled communications system. Project managers spend most of their time communicating with team members and other project stakeholders, whether they are internal (at all organisational levels) or external to the organisation [20].

Construction project involves diverse stakeholders with different cultural background, interest, and expertise; these variables could impact either negatively or positively on the project goals. Therefore, effective communication is needed to make sure that every stakeholder's interest and concerns are met. This further means that the project manager could fail in his/her function of management, if there is no effective communication management. For organisations to reap the full benefits of communications, efforts should be made to cultivate a culture of effective communications practice. According to Berrelas [22], effective communication is said to have taken place when the receiver understands the content of the message and react accordingly. When the initiator's intentions of a communicated massage are not misunderstood by the receiver, by way of acting in line with the content, the communication can be said to be effective.

\section{The flow of communication in construction organisations}

Like other cooperate organisation, the flow of communications could be within an organisation or between an organisation and another organisation. That is communication could be internal or external.

\section{A. Internal communication}

Internal communications occurs within an organisation and it plays a vital role in building a positive relationship between the superiors and subordinates or between employers and employees. All communications that take place within an organisation is called internal communication [23].The ability of an organisation to properly define and structure its internal communication system, will influence communication effectiveness and external communication.

\section{B. External Communication}

Takes place between an organisation and other external or outside organisations. It is that communication between a procurement manager with an external company or groups for the purpose of procuring materials, or getting a vendor for a product or services.), external communication assist in achieving company's bottom line, as it focuses on audiences outside the organization [24].

Communication can flow in 3 directions, namely;

1) Vertical flow of communication: this involves the up and down flow of information, thoughts and ideas 
within the organisational hierarchy. The vertical flow of communication is divided into downward and upward flow of communication.

$i$. Downward flow of communication is the flow of information, ideas, and thoughts, among others from a higher level in an organisation to a lower level [25]. It is communication from superiors to subordinates within the organisational command line. Instructions and directives related to the construction works are transmitted downwards from the site engineers, safety managers, supervisors to the construction filed operatives or tradespeople. Construction tradespeople need this information that is sent downward to carry out the various tasks that are required to meet the project objectives and the project managers' expectations.

ii. Upward Flow of Communication is the flow of information, thoughts, ideas, feelings, emotions, complaints; from a lower level to a higher level. On construction projects, upward flow of information enables subordinates, site operatives, artisans and other workers at the lowest part of the organisational hierarchy to convey the performances of their supervisors, managers and other senior workers to the management. Upwards communication is used to express how well the downward communications are understood by the construction tradespeople. An organisation that practice upwards communication will experience more workers commitment and loyalty.

2) Horizontal Communication is also regarded as lateral communication. It is the flow of information among people at the same level within the organisation hierarchy. It is communication between managers at the same level or between operatives at the same level. The horizontal communication enables the sharing of information, knowledge and experiences. It helps to facilitate cooperation and understanding among team members or trades groups, it facilitates decision making during work, thus, saving time of project execution. Conflicts between two units and/or departments are resolved without delays.

3) Diagonal Communication is the communication that occurs between a superior/manager and employees of other workgroup. This type of communication does not follow the organisational command line, thus, are not found the in the organisational chart. On construction projects for instance, a finishing managers trying to develop a method statement for laying granolithic flooring, will enquire from the safety personnel for its own safe method of executing the task.

From figure 1, the upward, downward and lateral flow of communication is displayed to represent the three major channels through which a project manager communicates. As earlier stated, during construction project execution, communications are initiated, transmitted through a pre-determined channel to the target audiences on construction site, project teams or outside the project organisations. The upward communication involves the use of various medium already approved by management for either written, verbal mean of communication to management from subordinates and other individuals. Information is pushed downwards to workers in an effective way to ensure that project goals are met. To ensure a good working relationship among peers or managers at the same level, horizontal (lateral) communications are allowed. A construction project with stormy work environment will not achieve its goal, because there will be multiple delays owing to crisis and disagreement. A good working relationship and environment where there is high level of interaction among workers is a key to helping construction project meet its planned schedules.

\section{Construction projects communication Models}

PMBOK Guide [20] presented a simple communication model which can be used to make communication easy at difference stages of construction projects. Depending on the magnitude or complexity and number of stakeholders involved in the project, the model can be modified to suite project conditions. The communication model in (figure 2) is for two parties (sender and receiver). With the approve mode of communication, the information, ideas, thoughts, instruction, amongst others, are transmitted through the use of technology as the medium.

Communication starts by the sender encoding his thoughts or ideas in a language that will be understood by the receiver. The massage is transmitted using the suitable channel to get it to the receiver. During the transmission of the message, the quality or meaning might be compromised by noise or interferences. These interferences could be space and time, insufficient infrastructure, unfamiliar technology, cultural difference, and absence of background information [20]. The receiver receives the message and tries to make sense or meaning of it (that is, decoding the ideas or thoughts). The receipt of the message is acknowledged to signal the sender that the message reached its target recipient. On construction sites, owing to the level of activities most messages are not immediately read even though acknowledgements are sent. Furthermore, acknowledgement most times does not mean that the contents of a communicated message are understood or comprehended.

It is the response or feedback that will give the sender an idea of whether his ideas or thoughts were understood, and this is will be evident in doing or following what the message says. 


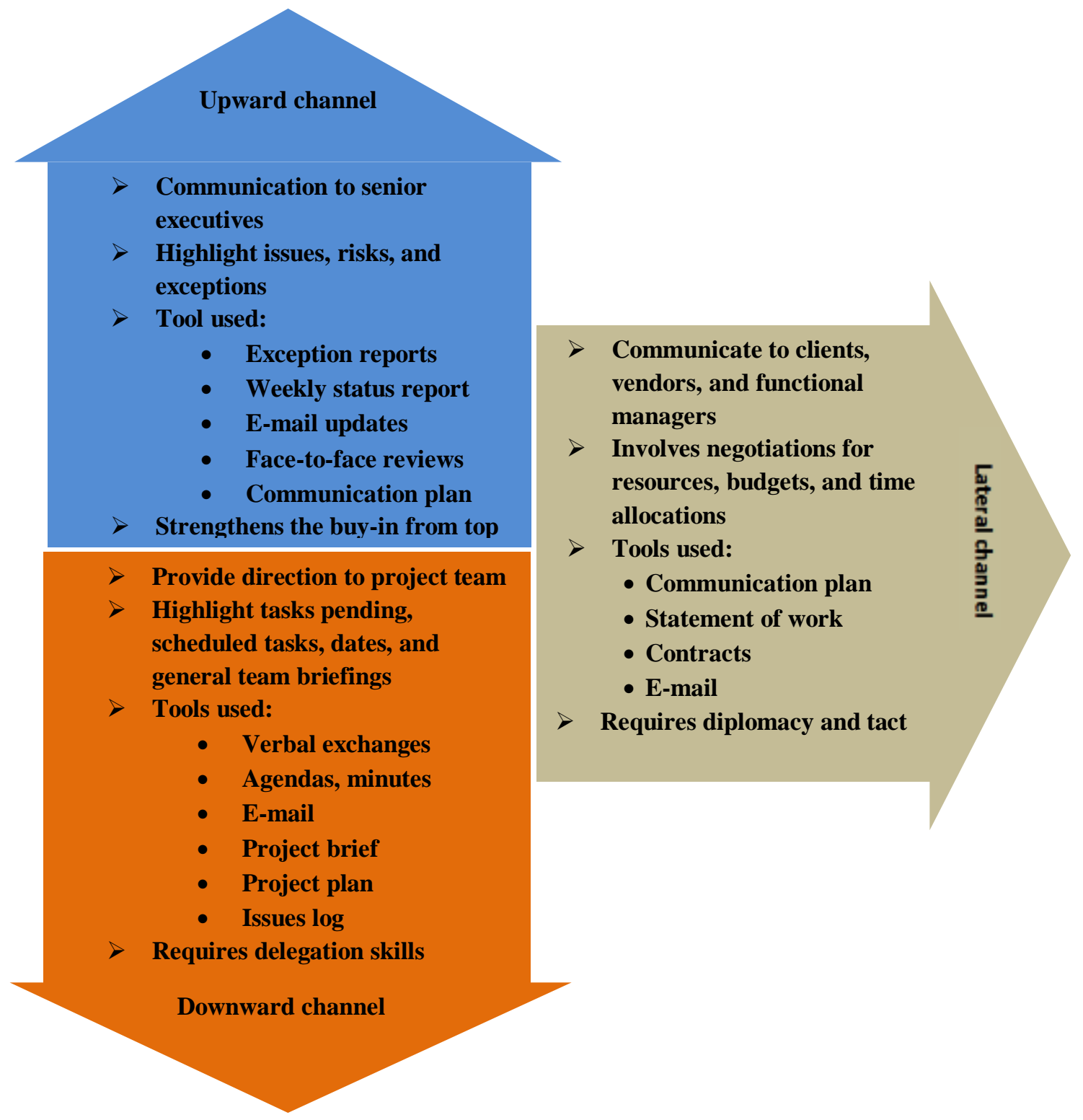

Figure 1: Communications channel of project manager Source: Modified from [26, 27,11] 


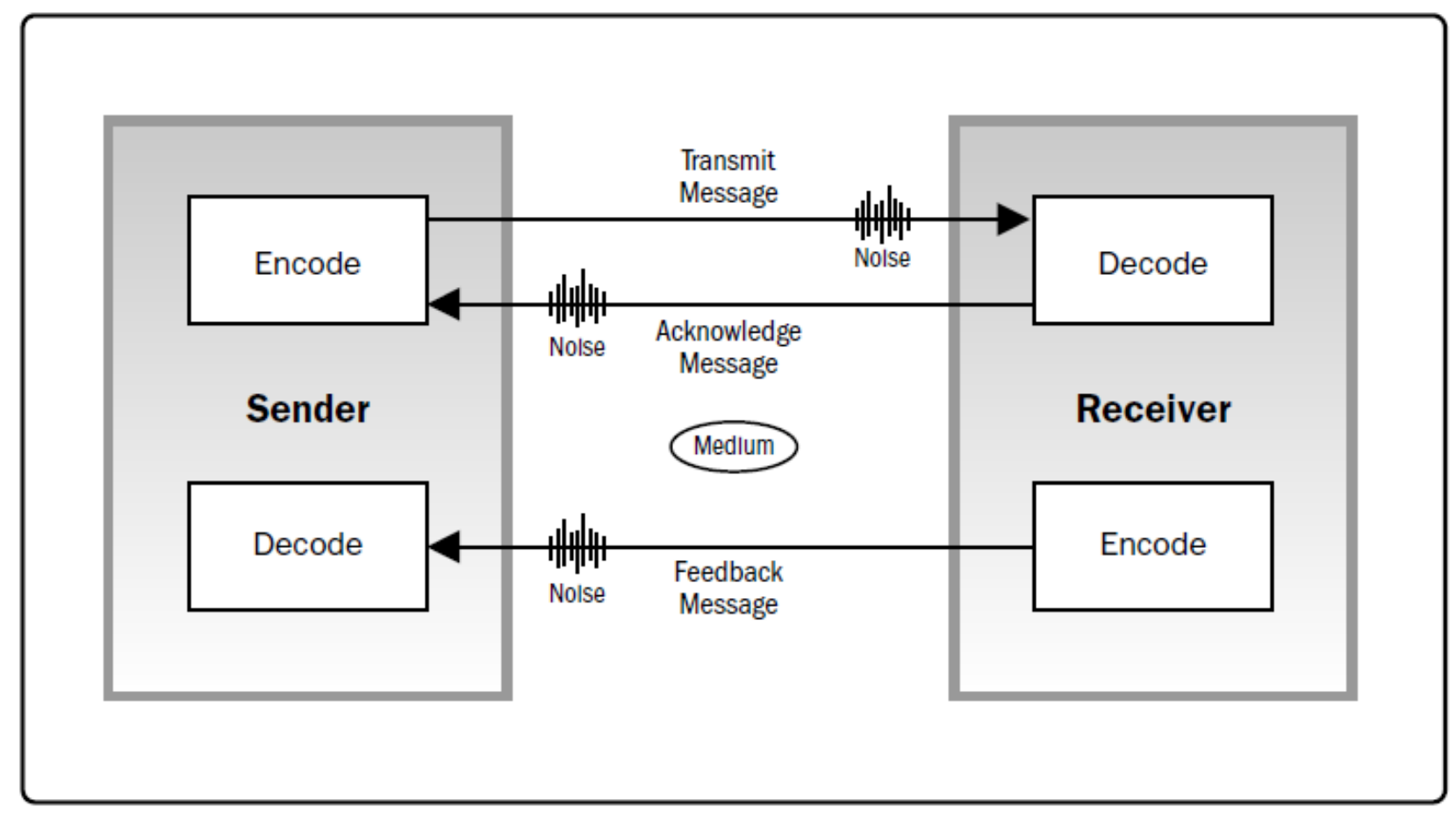

Figure 2: Basic communication model

Source: PMBOK Guide [20]

Causes and effects of ineffective communications on construction project

As the activities and operations and diversity of a construction site increase, the need to properly communicate becomes increasingly important. Organisations frequently find it impracticable to effectively communicate, even when communication is known to be vital for a successful working relationship [6], this is because communication is often taken for granted in most workplace environment [28]. Furthermore, organisations are always in a haste to get message across to their employees that effectiveness of the communicated message is ignored.

Effective communication occurs when the intended meaning of a communicated message is not misunderstood. Ineffective communication is a product of interference or noise during the transmission of the message across the medium or channel of communication. The noise interferes and distort the original meaning of the information contained in the message, thus, leading to breakdown, loss of quality and wrong decoding evident in the feedback. These noises constitute causes that compromise information exchange and ideas sharing. It is these causes and the effects of effective communication on construction projects that this study set to assess.

The major reasons for ineffective communication in workplaces according to [29] are; unclear goals and objectives, absence of information for the proper accomplishment of the tasks, poor leadership, personal issues, and cultural diversities. Mailabari [30] found that poor listening and premature evaluation, deferring perception, badly expressed message, experience in the field of work, inconsistent verbal and non-verbal communication, noise, information overload, distrust and emotional reaction; are the major inhibitors to effective communication in the construction industry. The lack of training and undertrained workforce contributes to communication issues and other management related problems. This could be the reason why [31] proposed the implementation of extensive training and learning that is compatible the requirements of multicultural team's communication needs. Gamil and Rahman [32] carried out a theoretical review of the causes and effects of poor communication and found that the most reoccurring causes in literature are; lack of effective communication between construction parties, lack of effective communication system and platform, poor communication skills, language barrier, improper communication channels, possessing different level of education among construction teams, lack of support for advanced communication technologies, diversity of culture and ethics among construction teams, personal barrier, and technology malfunction. Some of the common causes of poor communications in the workplace identified by [13] are; objectives are not clear, poor leadership, 
cultural diversity in the workplace, demoralized employees, personal issues, and challenges of employees. The most recurring effects of ineffective communication identified by [32] include; time overrun, conflict among construction parties, cost overrun, and rework and redesign occurrence, high accident rate, failure of the project, and demotivated workforces. A major leading cause of time and cost overruns on construction projects is poor communication among construction parties.

Tilipi et al. [11] found that communication ineffectiveness are caused majorly by; uncertain communication objectives, ineffective reporting system, imprecise channels of communication, insufficient communication between the parties on the project, language difficulties and stereotyping. Furthermore, they also confirmed that the effects of ineffective communication are project schedule delays, cost overrun, and project abandonment and limits the performance of professionals. Distance, poor equipment, use of old technology, lack of concentration, lack of training, lack of clarity of roles and responsibilities, lack of supervision, poor management, lack of consultations, resistance to change were examples of the physical, defective organisational structure and attitudinal barriers to effective communication. In addition, Illness poor feedback system and work pressure are some of the factors that leads to communication ineffectiveness on construction sites [9]. Similarly, Brookins [6] submitted that the reasons for poor communications in workplaces like the construction site are lack of leadership abilities, unclear goals and duties, undertrained employees, limited feedback, employees disengaged, and virtual teams. The factors responsible for ineffective communication in the workplaces are; poor workplace culture, unclear goals and lack of training, growing numbers of disengaged workers, poor management style, lack of preparation, and resorting to jargon [28].

The study carried out in Malaysia by [18] showed that the top ten effects of communication problems are; high stress in workplace, cost overrun, information overlapping conflict among construction parties (dispute), worsening relationship among construction parties, poor project planning, wrong execution of activities, poor risk management, time overrun and poor project information management. Time savings, increase in productivity and client satisfactions are identified by [9] to be the major effects of effective email communication on project performance. This implies that there will be time loss or overrun, decline in productivity and client dissatisfaction when there is ineffective email communication. Rahman and Gamil [18] found that the major causative factors of ineffective communication are; fear to communicate, delay notification of change, lack of sector experience, individual barrier (habits), poor progress measurement, contractual barriers (restrictions) and poor communication skills. The study advocated for more attention from academics and researchers to come up with innovative and more effective strategies and methods to eliminate poor communication in order to help improve project success and performance level.

The lack of effective communication has been identified in extant literature to be the key cause of time and cost overruns in construction. In the Egyptian construction industry, cost overruns have the highest impact at the design phase and it is caused by a lack of communication and coordination between design stakeholders of different background [33]. Also, poor communication among construction parties was among the factors responsible for cost overruns in Saudi Arabia [34]. Oluwaseun and Olumide [35] submitted that the absence of proper communication can cause delays if it is not part of the objective of the stakeholders. Rahman et al. [36] confirmed that poor communication is the major contributor to construction project schedule overrun. Improper communication channels, wrong design, slow information dissemination, wrong interpretations are the various forms in which ineffective communication take [11, 37, 38, 39]. According to Mehra [26], the means by which the scope of work and other details required for construction work are communicated through the use drawings (Architectural, structural and services), specifications and bill of quantities, contract documents and addenda. The importance of these indicates that if there is error in any of these documents, the project will suffer from not only delay but also budget overrun, claims, disputes, variations, reworks, safety issues, and in extreme case abandonment.

Dispute is one of the endemic and chronic features of the construction industry and it has been identified as a consequence of failed communications in organisations [32, 40, 41, 42]. Furthermore, the danger of disputes in construction made [43] to emphasize the importance of effective communication in improving the relationships that exist amongst construction project team. Defects in quality requirements and deviation in the delivery of materials occurs due to communication failure and ineffective communication among the concerned parties [44]. Efforts targeted at improving communication consistency, means and methods are required of the parties. Poor management of communication channels have resulted to concurrent communication among different department and units due to the complexity of construction projects. Effective channelling of communication should be practices in order to properly manage and control communication processes [45]. It was reported by [46] that the absence of appropriate data channels, unsuitable channels and wrong data transfer where the 
factors that inhibit heavily on effective communication on construction projects.

According to Kokemuller [12], the specific undesirable effects of ineffective communication include limited employee engagement, culture of distrust, ineffective customer interaction and uncertainty. The study pointed out that Ineffective communication makes building of trust impossible and also contributes to a culture of distrust in an organization. This is because trust is needed for the success of high-performing project team. It was also submitted that poor communication restrict relationships and employees level of engagement. The absence of good communication especially top-down, could lead to no clear direction for the role of departments/units and individual workers. Thus, the level of confusion will be high. Poor internal communication and poor coaching of frontline workers could result to poor communication with customers. This therefore hinders organisations from building or gaining customers loyalty. This even gets worst when there is not customer feedback system in place.

\section{MATERIALS AND METHODS}

The aim of this study is to examine the factors responsible for ineffective communication on construction projects. The study also sort to establish the major effects of ineffective communication and make recommendations for improving communications for better project performance. The study area is Edo state, Nigeria and a well-structured questionnaire was administered electronically to construction professionals who understands the workings and operations of their construction organisations and experienced in construction project communications management. According to Chidiebere et al. [47], construction professionals such as the Architects, Builders, Engineers (civil and services), and Quantity Surveyors form bulk of the major experts engaged by construction organisations (consultants and contractors). Thus, this study sorts the opinion of the construction professional in both consulting and contracting organisation on the subject of this study. Delta state is located in the Niger-delta region of Nigeria, and the region is known for the presence of oil and gas. This makes Delta state to be among the rich states and also one of the major contributors to the national revenue generation of Nigeria. The state is doing well in building and infrastructure provision anchored by both the federal and state governments. These attract a lot of companies both in construction and oil/gas exploration and servicing. The questionnaire was adopted because it's economical and suitable for covering wider participants in a shorter time. The use of electronic means for administering the questionnaire was to save time and cost, and to cover large participants who are impracticable to access.

The questionnaire was developed using information gathered from a detailed literature review. The research instrument was designed such that it has three sections. The first section was used for gathering data on the background of the respondents. The second part contained 24 selected factors responsible for ineffective communication on construction projects, and the last section contain 20 selected effects of ineffective communication on construction projects. The respondents were required in second and third sections to rate the variables in order of importance using a 5-point Likert scale, where 1 is lowest and 5 is the highest. The criteria for participation are that the respondents must have at least 5years working experiences, must be currently engage with a construction organisation/site, must have experiences in managing project communications and know how organisational communication works, and must be willing to participate in the survey. It is the understanding of this study that these criteria would enable quality and unbiased data to be collected.

The snowball sampling technique was adopted in the survey. This sampling method is efficient, economical and saves time and it is suitable for reaching groups with specific qualities who are difficult to access [48]. This sampling technique is based on referral and it has the tendencies to increase the sample size significantly [48, 49, 50]. Furthermore, establishing the sample population and size was difficult because a database of professionals with the criteria set for the study's participants was non-existence. This further made the snowball sampling technique suitable for the study. The questionnaire was delivered electronically in Google forms via emails and WhatsApp to the initial set of participants identified through a preliminary survey.

At the end of the 9 weeks sampling period, 123 responses were received and they were adjudged adequate for the data analysis. The gathered data were analysed using frequencies, percentages and relative importance index (RII). The gathered data were first subjected to reliability evaluation using Cronbach's alpha test. In all, the alpha's values obtain are 0.964 and 0.845 for case 1 and case 2 respectively (see Table 1 ). This result shows that there is a high reliability and internal consistency of the data collected. It also indicates a good quality data. Then, Relative importance index (RII) was used to analyse and rank the identified variables (factor responsible for ineffective communication and effects of ineffective communication). These variables were ranked in descending order based on their RII values 
Causes and Effects of Ineffective Communication on Construction Projects

Table 1: Reliability evaluation

\begin{tabular}{lcc}
\hline Assessed variables & $\begin{array}{c}\text { Cronbac } \\
\text { h's } \\
\text { Alpha }\end{array}$ & $\begin{array}{c}\text { Nr. of } \\
\text { items }\end{array}$ \\
\hline $\begin{array}{l}\text { Case 1: factor responsible for } \\
\text { ineffective communication }\end{array}$ & 0.964 & 24 \\
$\begin{array}{l}\text { Case 2: effects of ineffective } \\
\text { communication }\end{array}$ & 0.845 & 20 \\
\hline
\end{tabular}

\section{RESULTS AND DISCUSSION}

\section{Respondents background information}

Table 2 shows the result of the analysis of the information gathered on the respondents' background. It can be seen that $64.23 \%$ of the respondents' work with contracting organisations and $35.77 \%$ work with consulting organisation. This however, shows a fair representation of experiences from contractors and consultants. Furthermore, in terms of professional composition, $22.76 \%$ are architects, $13.82 \%$ are builders, $36.59 \%$ are engineers, and $26.83 \%$ are quantity surveyors. This is a fair representation of the key construction professional sampled. The highest educational qualification of the respondents shows that $29.27 \%$ had HND, $13.01 \%$ have PGD, $31.71 \%$ hold BSc./B.Tech., 23.58\% are MSc./M.Tech holders and $2.44 \%$ hold $\mathrm{PhD}$. This shows that the participants are educationally qualified to give an informed response that would aid the study. The years of experience showed that $33.33 \%$ of them have spent $5-10$ years in the industry, $37.40 \%$ had spent $11-15 y e a r s, 16.26 \%$ had spent $16-20$ years and $13.01 \%$ have spent over 21 years in the industry. This indicates that the participants are experienced enough to give reliable information regarding the subject of this study. The professional affiliation of the respondents shows that $90.24 \%$ of them are corporate members of their various professional organisations, and only $9.76 \%$ are still probationer members of the various professional organisations. This shows that the participants are professionally qualified to give quality information on the subject matter of this present study.

Table 2: Respondents background information

\begin{tabular}{llcc}
\hline Variables & Classification & Freq. & $\begin{array}{c}\text { Per } \\
\text { cent }\end{array}$ \\
\hline $\begin{array}{l}\text { Organisation } \\
\text { type }\end{array}$ & $\begin{array}{l}\text { Consulting } \\
\text { organisations }\end{array}$ & 44 & 35.77 \\
& $\begin{array}{l}\text { Contracting } \\
\text { organisations }\end{array}$ & 79 & 64.23 \\
& TOTAL & $\mathbf{1 2 3}$ & $\mathbf{1 0 0 . 0 0}$ \\
Respondents' & Architects & 28 & 22.76 \\
Profession & Builders & 17 & 13.82
\end{tabular}

Engineers (Civil \& Services) $\quad 45$

Quantity surveyors 33

TOTAL 123

36.59

26.83

Highest

educational

qualification

Higher national

Diploma (HND)

36

100.00

Postgraduate

Diploma (PGD)

Bachelor of

Science/Technology 39

(B.Sc./B.Tech)

Master's Degree

(MSc./M.Tech.)

Doctorate degree

$(\mathrm{PhD})$

TOTAL

16

13.01

39

29

3

2.44

Years of

experience

5-10years

123

100.00

$\begin{array}{lcc}11-15 \text { years } & 46 & 37.40 \\ \text { 16-20 years } & 20 & 16.26 \\ \text { 21-above } & 16 & 13.01 \\ \text { TOTAL } & \mathbf{1 2 3} & \mathbf{1 0 0 . 0 0}\end{array}$

professional

affiliation

MNIA

19.51

NIOB $\quad 14 \quad 11.38$

$\begin{array}{lll}\text { NSE } & 42 & 34.15\end{array}$

NIQS $\quad 31 \quad 25.20$

Probationer $\quad 12 \quad 9.76$

TOTAL

$123 \quad 100.00$

Level of communication practices in construction organisations

The respondents were asked to rate how best they can describe the level of communication practices of their organisations. The result shows that the level of communication practices in the organisations sampled ranges from low to moderate (see fig. 3). This implies that construction organisations still have a lot to do in the area of communication. This further explains why construction projects still experiences poor time, cost and quality performance. Poor construction project performance has been linked to ineffective or poor communication practices and management by construction organisations during construction projects execution. 


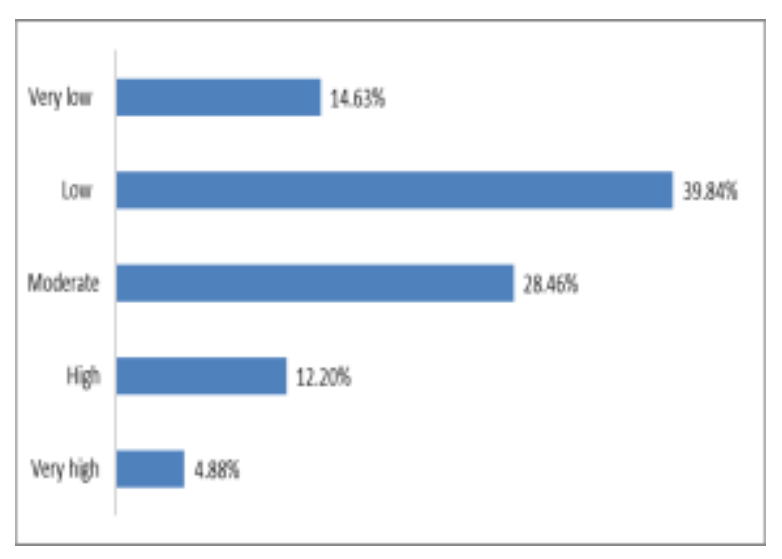

Figure 3: Level of communication practices in construction organisations

Level of importance of effective communication practices in helping individuals and organisational performance

The respondents were asked rate 'how important they think effective communication practices could be in helping them and their organisations perform better. The result shows that construction professionals perception of the level of importance of communication ranges from high $(43.09 \%)$ and very high $(34.15 \%)$ (See fig 4). This implies that communication is a key requirement for construction projects to be delivered. It is at the core of construction projects delivery. Communication binds all the units, departments, professionals, trade groups and project teams (design and construction) together. These finding shows that communication is still at the centre of every project management activities that are needed to deliver a project successfully.

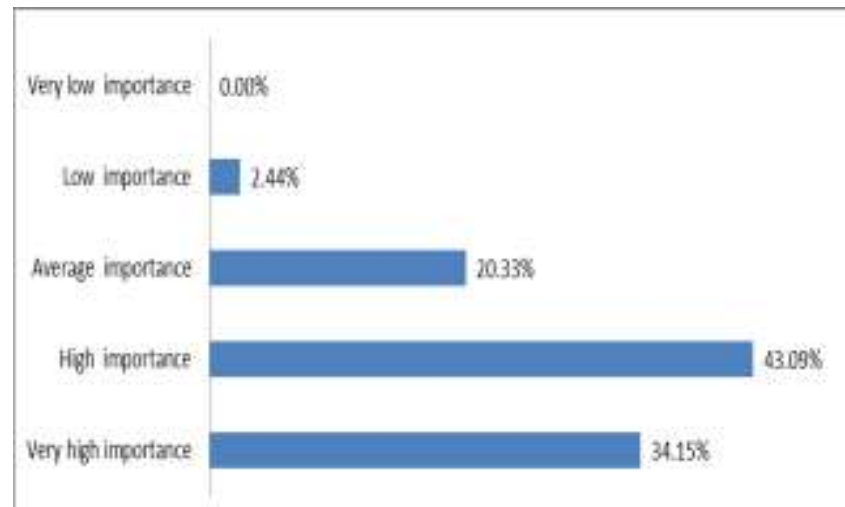

Figure 4: Level of importance of effective communication practices in helping individuals and organisational performance
Factors responsible for ineffective communication on construction projects

Table 3 shows the result of the analysis of the data collected on the factors responsible for ineffective communication on construction projects. The result showed that the top 10 causes of ineffective communication are; poor management and leadership abilities ( $\mathrm{RII}=0.928)$, lack of training and undertrained workers $(\mathrm{RII}=0.925)$, lack of support for advanced communication technologies ( $\mathrm{RII}=0.907)$, malfunction and/or use of out-dated technology $(\mathrm{RII}=0.904)$, poor communication skills $\quad(\mathrm{RII}=0.904)$ improper communication channels $(\mathrm{RII}=0.898)$, ineffective reporting system $(\mathrm{RII}=0.894)$, lack of concentration and work pressure $(\mathrm{RII}=0.889)$, unclear goals and objectives and responsibilities $(\mathrm{RII}=0.888)$, and ethics and cultural diversity of construction teams (RII=0.880). The least 5 causes of ineffective communication are; distance and space (RII=0.834), growing numbers of disengaged workers ( $\mathrm{RII}=0.833$ ), insufficient communication between the parties on the project $(\mathrm{RII}=0.826)$, possessing different level of education among construction teams $(\mathrm{RII}=0.763)$, and lack of supervision $(\mathrm{RII}=0.711)$. A cursory look at the RII values of the variables showed that the highest is 0.928 and the lowest is 0.711 ; thus, the RII ranges from high to very high. Furthermore, the average RII is 0.864 equivalent to $86.40 \%$, this implies that the all the assessed variables have high level of contribution to ineffective communication on construction projects.

Management and leadership are at the centre of construction project integration and communication management. Leaders lead by example and are not careless when it comes to communication. Good leadership ability will guarantee effective communication and it comes with a lot of responsibilities. Project communication management involves all the processes that are needed to guarantee timely and proper planning, collection, creation, distribution, storage, retrieval, management, control, monitoring, and the ultimate disposition of project information [20]. Poor leadership was identified by [29, $13,9,28,6]$, to be a one of the reasons for communication problems. It is the function of management to organise training and re-training programmes for its employees. An ill-trained worker is a potential source of risks to others, the project and to him/herself. Lack of training and undertrained workforce has been found to be responsible for ineffective communication [31, 9]. Training programmes improves the communications and interpersonal skills of the workforce. In addition, the absence of the needed support for modern technology implementation by management of construction organisations can impact on how managerial functions 
are discharge. Information dissemination is sustainable where innovative technologies are adopted for communication purposes. In a theoretical review of the causes and effect of poor communication, [32] reported that the lack of support for the adoption of advanced communication technologies contribute to ineffective communication in an organisation.

The result of this study also supports the submissions of $[6,13,18,9,28,11,29]$, on the roles of malfunction and/or use of out-dated technology, poor communication skills, improper communication channels, Lack of concentration and work pressure, unclear goals and objectives and responsibilities, and Ethics and cultural diversity of construction teams in contributing to ineffective communication in construction. A well-defined and properly articulated communications management plan will help in avoiding most of these causes and makes organisation to be better prepared for communication related challenges that might be encountered in the course of managing construction projects execution.

Table 3: Factors responsible for ineffective communication on construction projects

\begin{tabular}{clcc}
\hline S/No & Variables & RII & Rank \\
\hline 1 & Unclear goals and objectives and responsibilities & 0.880 & $9^{\text {th }}$ \\
2 & Absence of information for the proper accomplishment of the tasks & 0.867 & $14^{\text {th }}$ \\
3 & Poor management and leadership abilities & 0.928 & $1^{\text {st }}$ \\
4 & Personal issues & 0.870 & $13^{\text {th }}$ \\
5 & Ethics and cultural diversity of construction teams & 0.880 & $9^{\text {th }}$ \\
6 & Lack of motivation and demoralized employees & 0.852 & $18^{\text {th }}$ \\
7 & Ineffective reporting system & 0.894 & $7^{\text {th }}$ \\
8 & Improper communication channels & 0.898 & $6^{\text {th }}$ \\
9 & Insufficient communication between the parties on the project & 0.826 & $22^{\text {nd }}$ \\
10 & Language difficulties and stereotyping & 0.876 & $11^{\text {th }}$ \\
11 & Possessing different level of education among construction teams & 0.763 & $23^{\text {rd }}$ \\
12 & Lack of support for advanced communication technologies & 0.907 & 3 rd \\
13 & Malfunction and/or use of out-dated technology & 0.904 & $4^{\text {th }}$ \\
14 & Lack of training and undertrained workers & 0.925 & $2^{\text {nd }}$ \\
15 & Resistance to change & 0.860 & $16^{\text {th }}$ \\
16 & Poor feedback system & 0.862 & $15^{\text {th }}$ \\
17 & Health issues (hearing/vision problems) & 0.857 & $17^{\text {th }}$ \\
18 & Lack of concentration and work pressure & 0.889 & $8^{\text {th }}$ \\
19 & Distance and space & 0.834 & $20^{\text {th }}$ \\
20 & Growing numbers of disengaged workers & 0.833 & $21^{\text {st }}$ \\
21 & Lack of preparation and use of technical jargons & 0.844 & $19^{\text {th }}$ \\
22 & Poor communication skills & 0.904 & $4^{\text {th }}$ \\
23 & Poor listening and premature evaluation & 0.873 & $12^{\text {th }}$ \\
24 & Lack of supervision & 0.711 & $24^{\text {th }}$ \\
\hline
\end{tabular}

\section{Effects of ineffective communication on construction}

Results in table 4 show the effects of ineffective communication and their ranking. It can be seen that the top five major effects are; cost overrun (RII $=0.948)$, time overrun (RII=0.915), high accident rate (RII=0.902), wrong execution of activities ( $\mathrm{RII}=0.889)$, and rework and redesign occurrence $(\mathrm{RII}=0.880)$. Also, the least five effects of ineffective communication construction projects are; waste generation (RII $=0.764)$, uncertainty and confusion $(\mathrm{RII}=0.745)$, distrust and worsening relationship among construction parties (RII=0.719), limits the level of engagement and performance of professionals (RII=0.711), and ineffective customer interaction (RII=0.691). Regardless of the ranking, all the effects of ineffective communication ranges from moderate to very high as evident in the RII range (highest $=0.948$ and lowest $=0.691$ ). With an average RII of 0.818 $(80.8 \%)$, the effects of ineffective communication can be said to be high. 
The result of this section is in line with the findings of $[32,11,18,34,35,36,37]$. These studies reported that poor communication have effect on project time and cost. Thus, the persistent time and cost overruns are majorly causes by ineffective communication. Rework and redesign leads to demotivation, loss of interest on the part of the workforce. Rework also exposes workers to accidents, as they most times not planned. Gamil and Rahman [32] reported that rework and redesign occurrence and high accident rate are part of the effects of poor communication on construction projects. Ineffective communication leads to insufficient instruction that can result in work being executed in the wrong sequence. [18] identified wrong execution of activities as a product of poor communication. Since, rework, accidents and wrong execution of activities lead to delay and extra cost. It can be said that the greatest effect of ineffective communication on construction projects is cost and time overruns.

Table 4: Effects of ineffective communication on construction projects

\begin{tabular}{clcc}
\hline S/no. & Variables & RII & Rank \\
\hline 1 & Time overrun & 0.915 & $2^{\text {nd }}$ \\
2 & Conflict and disputes among construction parties & 0.844 & $9^{\text {th }}$ \\
3 & Cost overrun & 0.948 & $1^{\text {st }}$ \\
4 & Rework and redesign occurrence & 0.880 & $5^{\text {th }}$ \\
5 & High accident rate & 0.902 & $3^{\text {rd }}$ \\
6 & Demotivated workforces & 0.863 & $6^{\text {th }}$ \\
7 & Project abandonment & 0.792 & $13^{\text {th }}$ \\
8 & Limits the level of engagement and performance of professionals & 0.711 & $19^{\text {th }}$ \\
9 & High stress in workplace & 0.766 & $14^{\text {th }}$ \\
10 & Distrust and worsening relationship among construction parties & 0.719 & $18^{\text {th }}$ \\
11 & Poor project planning & 0.836 & $10^{\text {th }}$ \\
12 & Wrong execution of activities & 0.889 & $4^{\text {th }}$ \\
13 & Poor risk management & 0.810 & $12^{\text {th }}$ \\
14 & Poor project information management & 0.766 & $14^{\text {th }}$ \\
15 & Quality deviation & 0.847 & $8^{\text {th }}$ \\
16 & Wrong delivery of materials & 0.816 & $11^{\text {th }}$ \\
17 & Ineffective customer interaction & 0.691 & $20^{\text {th }}$ \\
18 & Uncertainty and confusion & 0.745 & $17^{\text {th }}$ \\
19 & Low productivity & 0.854 & $7^{\text {th }}$ \\
20 & Waste generation & 0.764 & $16^{\text {th }}$ \\
\hline
\end{tabular}

\section{Fishbone diagram of ineffective communication}

Following the results obtained on the factors responsible for ineffective communication and the effects of the factors on the performance of construction projects, a cause and effect diagram (see fig. 5) was developed. Figure 5 shows the top ten causes and top 5 effects of ineffective communication on construction projects. It can be seen that ineffective communication have the capability of killing a project because when the key project performance measurement baselines are affected, a project can be killed prematurely because the aim/purpose are already badly affected. 


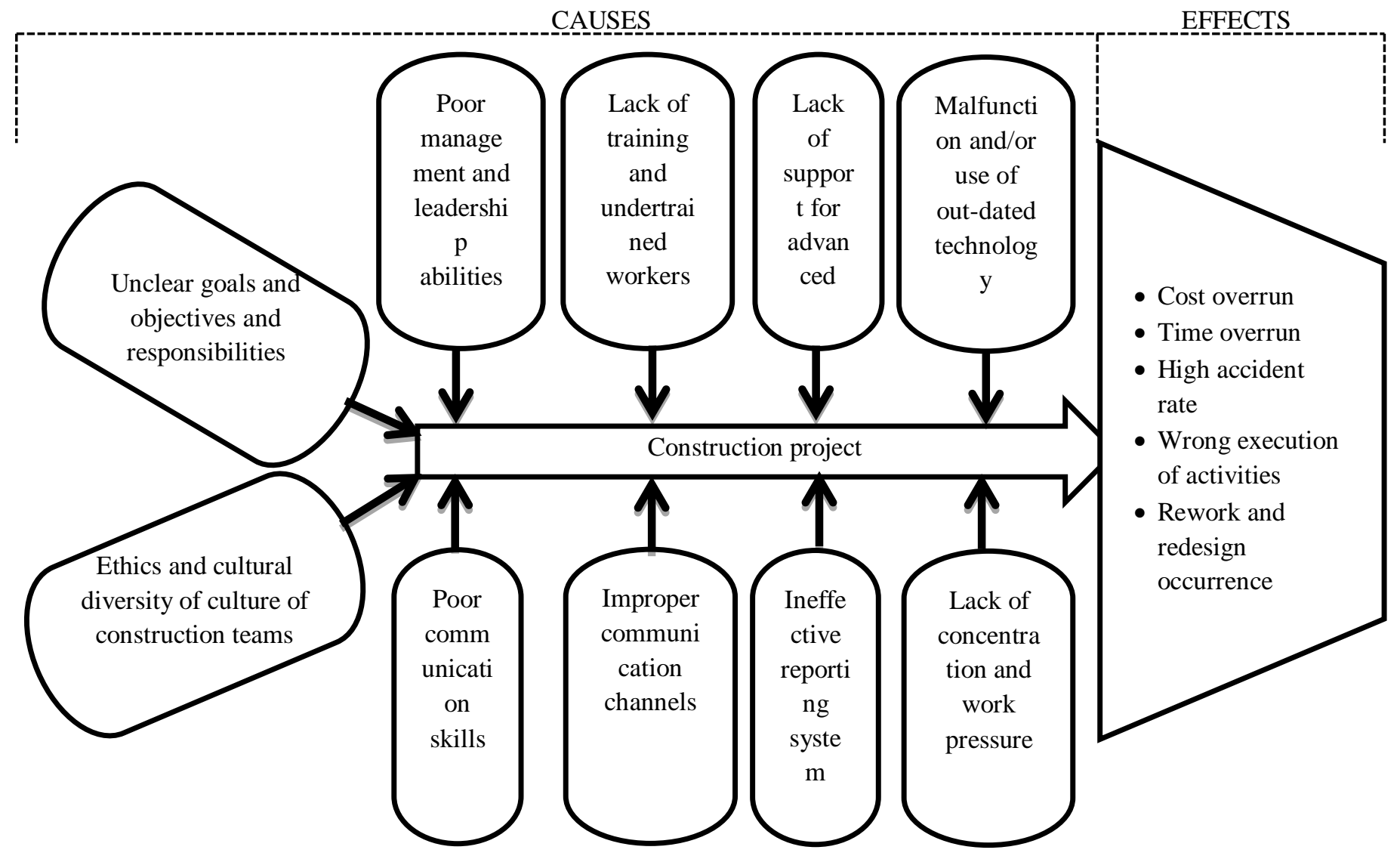

Figure 5: Fishbone diagram of ineffective communication

\section{CONCLUSION}

This study examined the factors responsible for ineffective communication on construction projects. It also assessed the effects of ineffective communication on construction projects. By utilising data collected using a well-structured questionnaire administered to construction professionals in Delta state, Nigeria, using snowball sampling technique; the study was able to determine the major causes of ineffective communication and the major effects of ineffective communication on construction projects.

The study found that construction organisations are still lagging behind in the practice of effective communication. Also, communication is a project integration tool for a successful delivery of construction contracts. The factors responsible for ineffective communication on construction projects are management and leadership abilities, lack of training and undertrained workers, lack of support for advanced communication technologies, malfunction and/or use of out-dated technology, poor communication skills, improper communication channels, ineffective reporting system, lack of concentration and work pressure, unclear goals and objectives and responsibilities, and ethics and cultural diversity of construction teams. These factors were found to have high level of contribution to ineffective communication on construction projects. The major effects of ineffective communication on construction projects are; cost overrun, time overrun, high accident rate, wrong execution of activities, and rework and redesign occurrence. Therefore, the effect of ineffective communication on construction projects is high.

In order to improve communication on construction projects and to minimise the effect of ineffective communication, the following recommendations were made;

1. The engagement of project managers who are experience in managing multicultural workforce and that have appropriate qualities and capabilities for managing very effectively project resources. Communication is one of the core functions of management and should be taken seriously by the lead project manager.

2. Construction workers should be adequately trained on how to communicate effectively with their supervisors and other managers to whom they report to. Training and retraining of workers are 
required to improve their communication skills, and encourage knowledge sharing.

3. Management support is also a key to overcoming poor communication. Adequate budget should be provided for the procurement of modern communication technologies for use in the organisation, for effective information dissemination. Also, with management support obsolete technologies are replaced and malfunctioning ones are repaired and properly maintained.

4. Every organisation should develop communication plan for managing and controlling communications on construction sites. The plan will normally define the channels and reporting and feedback systems of communications.

5. All sources of distractions should be removed from the vicinity of the working areas to avoid loss of concentration during communication. Site offices should also be located away from plant yards, batching plants, working areas, among others to avoid noise and distractions. Also, tasks should be properly planned and schedule to avoid overload and work pressure.

6. Employees' roles should be clearly described from inception so that they know their responsibilities and have prior knowledge of what is expected of them. The workforce should be adequately briefed about the goals of the project.

7. Different communication systems and methods should be put in place by construction organisation to accommodate cultural diversity among project team and to ease information dissemination and knowledge management.

The management of construction organisations will find this study useful in areas of communication planning and risks management. The key factors are identified and appropriate response plans developed to mitigate their occurrence. Construction organisations will also take advantage of this study by improving on their communication practices in order to improve project performance. Ineffective communication causes poor project performance, therefore, it should be avoided if success must be achieved in delivery of projects. This study adds to the available body of knowledge on communications in the construction industry.

This study is limited by its sample size and geographical boundary, this, therefore, makes it necessary for care to be taken in generalizing the findings. A similar study could be carried out in other states, region of Nigeria or even in other developing countries of the world or of Africa with similar construction atmosphere with Nigeria. This will make it possible for results to be compared. Construction artisans, craftsmen and operative who do the actual work execution, also have a role to play in communication because they are the final consumer of information from management in a vertical communication channel. Based on this, a study that will assess the perception of this group of workers should be carried out.

\section{REFERENCES}

[1] Eze,C.E., Awodele, I. A., Adegboyega, A. A., Onyeagam, O.P., and Guto, J.A. (2020). Assessment of the Triggers of Inefficient Materials Management Practices by Construction SMEs in Nigeria. International Journal of Real Estate Studies, 14(1), 38-56.

[2] Akinradewo, O.F., Ojo, L.D., and Oyefusi, O.N. (2017). Effects of communication among professionals on building projects delivery in Nigeria. Journal of Contemporary Research in the Built Environment, 1(2), 50-66.

[3] Calvert, R.E., Bailey, G., and Coles, D. (2003). Introduction to Building Management. Butterworth - Heinemann. Oxford; Great Britain.

[4] Alshawi, M., and Ingirige, B. (2003). Web-enabled project management: an emerging paradigm. Automation in construction,12(4), 349-364.

[5] Jimoh, R. (2012). Improving site management practices in the Nigerian construction industry: The Builders' Perspective. Ethiopian Journal of Environmental Studies and Management, 5(4). doi: 10.4314/ejesm.v5i4.5

[6] Brookins, M. (2020). Reasons for Poor Communication in the Workplace. Available at: https://smallbusiness.chron.com/reasons-poorcommunication-workplace-10137.html

[7] Olanrewaju, A., Tan, S. Y., and Kwan, L. F. (2017). Roles of Communication on Performance of the Construction Sector. Procedia Engineering, 196, 763-770. doi: 10.1016/j.proeng.2017.08.005

[8] Aiyewalehinmi, E. O. (2013). Factors analysis of communication in the construction industry. International Journal of Engineering and Science, 2(10), 49-57.

[9] Yakubu, G.A., Ogunsanmi, O.E., and Yakubu, A.O. (2019). Influences of communication problems on project performance in Nigeria. African Journal of Engineering Research, 7(3), 74-84.

[10]Foley. J., and Macmillan, S. (2005). Patterns of Interaction in Construction ream meeting. CoDesign, $\quad 1(1), \quad 19-37 . \quad$ DOI: 10.1080/1571088041233128992

[11] Tipili, L. G., Ojeba, P.O., and Ilyasu, M.S. (2014). Evaluating the effects of communication in construction project delivery in Nigeria. Global Journal of Environmental Science and Technology, 2(5), 048-054 
[12] Kokemuller, N. (2019). How Does Poor Communication Affect an Organization? Available at: https://bizfluent.com/info-8380825-poorcommunication-affect-organization.html

[13]Anton, V. (2017). The causes of poor communication in the workplace. Available at: https://www.alert-software.com/blog/the-causesof-poor-communication-in-the-workplace

[14] Agarwal, S., and Garg, A. (2012). The Importance of Communication within Organizations: A Research on Two Hotels in Uttarakhand. IOSR Journal of Business and Management (IOSRJBM), 3(2), 40-49.

[15]Nebo, C. S., Nwankwo, P. N., and Okonkwo, R. I. (2015). The Role Of Effective Communication On Organizational Performance: A Study of Nnamdi Azikiwe University, Awka. Review of Public Administration and Management , 4( 8),131-148.

[16] Stephen, C. (2011). Research methodology in Business and social sciences, Owerri, Canon

[17] Shonubi, A. O., and Akintaro A. A. (2016). The Impact of Effective Communication on Organisational Performance. The International Journal of Social Sciences and Humanities Invention, 3(3), 1904-1914.

[18] Rahman, I.A., and Gamil, Y. (2019). Assessment of Cause and Effect Factors of Poor Communication in Construction Industry. IOP Conf. Series: Materials Science and Engineering, 601,1-8. doi:10.1088/1757-899X/601/1/012014

[19] Ishaq, I. M., Omar, R., and Mohammed, M.(2018). Challenges of Communication between the Client and Contractor during Construction Projects: The Nigerian Perspective. International Journal of Engineering and Modern Technology, 4 (2), 20-29

[20] PMBOK Guide (2013). A guide to the project management body of Knowledge (PMBOK Guide).(5th ed.). Project management institute, Newtown Square, Pennsylvania.

[21] Antonio, S., and Senol, G. (2012). Non-Verbal Cues: Improving Communication. American Society for Engineering Education. AC 2012-3573

[22] Barrelas, A. (2010). An Experimental Approach to Organization Communication: Heinemann publishers, London, 28-35.

[23] Robu, M. D. (2010). The Communication Impact on the Productivity Growth of Human Resources. Romania: Acta Universitatis Danubius.

[24] Saunders M. (1999). Linking External Communication \& Organizational Effectiveness. Organizational Development Journal, 17(4),35-40

[25] Juneja, P. (n.d.) Importance of communication in an organization. Available at: https://managementstudyguide.com/importance-ofcommunication.htm.
[26] Mehra, S. (2009). Project communication Management. Available at: http://www.scribd.com/doc/7875707/ProjectCommunication-Summary-by-Sachin-Mehra.

[27] Keyton, J. (2011). Communication and organizational culture: A key to understanding work experiences. Thousand Oaks, CA: Sage.

[28] Poppulo (2019). 7 Factors that influence ineffective communication. Available at: https://www.poppulo.com/blog/factors-thatinfluence-ineffective-communication/

[29] HR Success Talk (2017). 5 Reasons of Poor Communication at Workplace. Available at: https://hrsuccesstalk.com/2017/01/29/5-reasons-ofpoor-communication-at-workplace/

[30] Mailabari, H.K. (2014). Assessment of Barriers To Communication In The Nigerian Construction Industry. MSc. thesis, Ahmadu Bello University Zaria, Nigeria.

[31] Culo, K., and Skendrovic, V. (2010). Communication management is critical for project success. Informatol, 43(3), 228-235.

[32] Gamil, Y., and Rahman, I.A. (2017). Identification of Causes and Effects of Poor Communication in Construction Industry: A Theoretical Review. Emerging Science Journal, 1(4), 239- 247.

[33] Bassioni, H.A., Sarhan, A., and Zaki, A.S. (2013).Cost overrun causes related to the design phase in the Egyptian construction Industry. Journal of Engineering Management Research, 1(5), 138-147.

[34] Alhomidan, A. (2010). Factors affecting cost overrun in road construction projects in Saudi Arabia. International Journal of Civil \& Environmental Engineering, 13(3), 1-4.

[35] Oluwaseun. S. D., and Olumide, A. A. (2013). Causes, effects and remedies of errors in Nigerian construction documents. Organization, Technology \& Management in Construction: An International Journal, (2013) 5(1), 676-686.

[36] Rahman, A., Memon, A., and Latif, Q. (2012). Time and Cost Performance of Construction Projects in Southern and Central Regions of Peninsular Malaysia. Retrieved from https://core.ac.uk/download/pdf/12008294.pdf

[37] Dainty, A, Moore, D and Murray, M. (2006). Communication in construction: Theory and practice, Taylor \& Francis, London.

[38] Sambasivan, M., and Soon, Y. W. (2007). Causes and effects of delays in Malaysian construction industry. International Journal of project management, 25(5), 517-526.

[39] Love, P. E., and Li, H. (2000). Quantifying the causes and costs of rework in construction". 
Construction Management \& Economics, 18(4), 479-490.

[40] Sinha, M., and Wayal, A. S. (2007). Dispute Causation in Construction Projects. IOSR Journal of Mechanical and Civil Engineering (IOSRJMCE).1(13),54-58. Retrieved from: https://www.iosrjournals.org/iosrjmce/papers/sicete(civil)-volume1/13.pdf

[41] Chan, D., and Kumaraswamy, M. (2002). Compressing construction durations: lessons learned from Hong Kong building projects. International Journal of Project Management, 20(1), 23-35.

[42] Loosemore, M., and Muslmani, H. A. (1999). Construction project management in the Persian Gulf: inter-cultural communication. International Journal of Project Management, 17(2), 95-100.

[43] Enshassi,A., Al-Najjar, J., and Kumaraswamy, M. (2009). Delays and cost overruns in the construction projects in the Gaza Strip. Journal of Financial Management of Property and Construction,14(2), 126 - 151.

[44] Darvik, L., and Larsson, J. (2010). The Impact of Material Delivery-Deviations on Costs and Performance in Construction Projects. Master's Thesis in the Design and Construction Project Management. Chalmers University of technology. Sweden.

[45] Fichet, H., and Giraud, L. (2007). How the information flow is processed in project-based companies compared to others and how it affects strategic drift. Master thesis. UMEA school of business .Sweden.

[46] Lee, J., and Bernold, L. E. (2008). Ubiquitous agent-based communication in construction. Journal of Computing in Civil Engineering, 22(1), 31-39.

[47] Chidiebere, E.E., Ikemefuna, O.H., Abraham, A.I., and Olalekan, O.K. (2020). Benefits of Innovative (ICT) Facilities Deployment on Construction Projects Delivery in Nigeria. Borneo Journal of Social Science and Humanities, 1(04), 1-16.

[48] Naderifar, M., Goli, H., and Ghaljaie, F. (2017). Snowball Sampling: A Purposeful Method of Sampling in Qualitative Research. Strides Dev Med Education, 14(3), 1-6. doi: 10.5812/sdme.67670.

[49] Ramsey, S. R., Thompson, K. L., McKenzie, M. and Rosenbaum, A. (2016). Psychological research in the internet age: The quality of web-based data. Computers in Human Behavior, 58, 354-360. doi: 10.1016/j.chb.2015.12.049

[50] Atkinson, R., and Flint, J. (2001). Accessing hidden and hard-to-reach populations: snowball research strategies. Social Research Update, Vol. 33. Available at: https://www.researchgate.net/ 